\title{
Mechanical and Dynamic Properties of Hybrid Composite Laminates
}

\author{
N. M. Mohamed*, M. S. EL-Wazery ${ }^{\dagger}$, M. I. EL-Elamy ${ }^{\ddagger}$, S. H. Zoalfakar ${ }^{\S}$
}

\begin{abstract}
Unsaturated polyester-based composites and reinforced with three types of fabrics, E-glass, basalt, and carbon, were fabricated by Hand-Lay Up (HLU) technique at room temperature, with various fiber configuration. Monotonic mechanical properties of hybrid composites laminate such as the tensile, flexural, inter-laminer shear strength and impact strength were investigated. The dynamic response of hybrid laminates composite under pulse load was studied theoretically and experimentally. In the theoretical part, the validity of the theoretical model for evaluating natural frequencies, mode shapes and dynamic response of hybrid composite laminates at various staking sequence has been examined by utilizing of the finite element software (ANSYS). In the experimental part, the response of hybrid composite specimens with various types of fiber configuration and four types of boundary fixations was measured by hammer test technique "frequency response function" (FRF).
\end{abstract}

The results show that the reinforcement by adding the basalt fabric and carbon fabric based unsaturated polyester composites as a fiber configuration $[2 \mathrm{C} / \mathrm{B} / 2 \mathrm{C}]_{\mathrm{S}}$ enhanced the mechanical properties of the hybrid composite laminates among other various stacking sequences. For the stacking sequence $[2 \mathrm{C} / \mathrm{B} / 2 \mathrm{C}]_{\mathrm{S}}$, it was found that the largest values of tensile, flexural strength and interlaminar shear strength (ILSS) were $128.76 \mathrm{MPa}, 405 \mathrm{MPa}$, 20.25 MPa, respectively. The results show the good bonding adhesion at the interface between the fibers and matrix of the hybrid composite laminates. The impact properties with stacking sequences [C-C-G-C-C]s have the largest value at 3.73 Joule as compared with the other composites and stacking sequences of all hybrid composite laminates. Also, the BFRP composites specimen gives the best vibration resistance compared to the other stacking sequences of hybrid composite laminates. The comparison between experimental and numerical model shows the efficiency of the proposed mathematical model of the composite structural specimen with bonded joints.

Keywords: Hybrid composite laminates, Carbon fiber, Hand-Lay Up (HLU) technique, Frequency response function (FRF), Bonded joint.

Enginer, Department of Production Engineering and Mechanical Design, Faculty of Engineering, Menoufiya University, Shebin El-Kom, EGYPT

$\dagger$ Lecturer, Department of Production Engineering and Mechanical Design, Faculty of Engineering, Menoufiya University,Shebin El-Kom, EGYPT. Corresp. auther: Eng_mahmoudsamir@yahoo.com

* Lecturer, Department of Production Engineering and Mechanical Design, Faculty of Engineering, Menoufiya University, Shebin El-Kom, EGYPT

$\S$ lecturer, Department of Mechanical Engineering, The Higher Technological Institute 10th of Ramadan City, EGYPT. 


\section{Introduction}

Hybrid composites have been used successfully in many industries such as aerospace components, automotive, wind power generation, containers, interior wall of a soundproofing room and Nano-technology [1]. Composite laminates offer alternative material design solutions in terms of specific strength and stiffness allowing important weight savings. They also offer significant freedom to the designer by allowing optimizing the strength and stiffness of a component or a structure for a particular application [2]. The development of composite materials improves their performance based on the reinforcement of two or more fibers in a single polymeric matrix which leads to the advanced material system called hybrid composite with a great diversity of material properties [3].

The mechanical properties of the E-glass and basalt fiber reinforced plastic laminates were carried out. It was found that the basalt material giving a high performance of the of the Young's modulus, compressive and bending strength [4]. The mechanical characterization of basalt-fiber reinforced epoxy composite, manufactured at various ratios such as 35:65, 40:60, 45:55 (Fiber: Resin) was studied [5]. The fiber resin ratio 45:55 gave more tensile and impact strength as comparing to other ratios. Derogate and Pergoretti [6] presented the flexural and impact behavior of carbon/basalt fibers hybrid laminates. The introduction of basalt fibers in the carbon fiber laminates could promote an increase of the impact energy. The flexural strength and flexural modulus of carbon and glass fibers reinforced epoxy hybrid composites were studied. It was found that the hardness, flexural strength and flexural modulus were improved as the fiber reinforcement contents were increased [7]. Amuthakkannan et al. [8] realized a comprehensive study about the mechanical properties of Basalt fiber and Glass fiber reinforced hybrid composites by using the compression moulding techniques. It was concluded that the composite material containing the combination (4B/8G) gave the maximum impact strength compared to the various stacking sequences of basalt and glass fabricated hybrid composites. Subagia and Kim [9] declared the performances of the carbonbasalt/epoxy hybrid composites under flexural loading manufactured by the vacuum assisted resin transfer molding process. It was found that the flexural properties of carbonbasalt/epoxy hybrid composites depended on the stacking sequence of carbon and basalt fabric. Rosa et al. [10] employed the impact properties of different configurations of hybrid laminates including E-glass and basalt fiber composites. Interlaminar shear strength tests and four-point flexural tests of laminates impacted with different energies have been investigated. The improvement in the mechanical properties has been obtained by intercalating single layers of E-glass and basalt laminates. Soare et al. [11] investigated the tensile, compression, shear and flexural tests of a basalt fiber composite in an unsaturated polyester matrix. The modulus of elasticity in compression was about $24 \%$ higher than the other in bending. It was found that the Young's modulus place the basalt fibers in between E-Glass fiber composites and carbon fiber composites. The interlaminar shear strength (ILSS) of glass and carbon fiber reinforced epoxy hybrid composite was studied. The ILSS of hybrid composite was improved as compared to glass fiber reinforced composite/carbon fiber reinforced composite [12]. The mechanical properties of carbon $(\mathrm{C})$, basalt $(\mathrm{B})$, and their hybrid combinations (BC, $\mathrm{CBC}$, $\mathrm{CCB}, \mathrm{BBC}$, and $\mathrm{BCB})$ of multiple layers at elevated temperatures have been investigated [13]. The results show that the carbon laminates had the highest elastic modulus and tensile strength at room temperature. However, the carbon laminates gave the greatest mechanical degradation at elevated temperature. Gururaja and Harirao [14] prepared the Hybrid composites with different angle ply orientation of carbon/glass with epoxy resin as an adhesive. Three orientations $0^{\circ} / 90^{\circ}, 45^{\circ} / 45^{\circ}$ and $30^{\circ} / 60^{\circ}$ were investigated. It was found that angle ply orientation at $0^{\circ} / 90^{\circ}$ gave significant increase in tensile properties as compared to other orientation. The influence of external layers of basalt-mat on the durability behavior of flax reinforced epoxy composites was evaluated. It was found that flexural properties of flax 
basalt composites were higher than those of pure flax [15]. A new combination of fiber metal laminates, termed Thermoplastic fiber-metal laminates (TFMLs), based on an aluminum alloy (2024-T3) and a self-reinforced polypropylene (SRPP) has been investigated. The TFML panels exhibit a poor performance under impact conditions involving high level of deformation and fracture [16].

The effect of number of carbon layer on the natural frequency and mode shape for hybrid fiber (carbon/glass) with epoxy composite laminates were investigated. The natural frequencies increased when the number of carbon/epoxy layers [17]. Mohammed et al. [18] examined experimentally the dynamic characteristics of laminated composite beams with different fiber orientations. The changes in fiber angle yield to different dynamic behavior of the component, that is, different natural frequencies for the same geometry, mass and boundary conditions. The energy absorption and dynamic response of different combinations of unidirectional glass and graphite fiber/epoxy hybrid composite were investigated [19]. It was observed that $60 \%$ graphite has the highest ultimate compressive strength. The ultimate compressive strength was also greater with higher percentage of graphite. Yokoyama et al. [20] assessed the behavior of carbon/epoxy laminates in all three principal material directions under high strain rate compression test. They found that by increasing strain rate leads to an increase in ultimate strength while the energy absorbed up to failure strain decreased. The influence of stacking sequence of composite laminates on static and dynamic mechanical properties was investigated [21]. It was found that the hybrid laminate with carbon fiber performs better than other hybrid arrangement. Ghosh et al. [22] investigated the dynamic mechanical analysis of FRP composites based on different fiber reinforcements and epoxy resin as the matrix material. Jacob et al. $[23,24]$ demonstrated the evaluation of dynamic mechanical properties of natural fiber reinforced polymer composites.

The present paper investigated the effect of the stacking sequences of unsaturated polyesterbased carbon/glass/basalt laminates on the mechanical properties such as the tensile strength, flexural strength, flexural modulus, interlaminar shear strength (ILSS) and charpy impact strength and the dynamic behavior such as natural frequency, damping factor and mode shapes with four types of boundary fixations by using the frequency response function" (FRF) and finite element software package (ANSYS).

\section{Experimental Work}

\subsection{Materials}

Plain weave such as: carbon fabric (C120-3K), glass fiber (E-Glass) and basalt fabric (EcoB4F210) were used as reinforcements in the form of hybrid composites laminates. The specifications of the three types of fibers were listed in Table 1. The unsaturated polyester resin (HTC-667C) with catalyst addition as matrix for the hybrid composite laminates was used [25]. The characteristics of the unsaturated polyester resin were listed in Table 2. In this experiment $22.3 \mathrm{wt}$. \% hardener was mixed with resin to form the matrix. The total weight fraction of the fibers was about $60 \%$.

Table 1. Specification of carbon, glass and basalt fibers [25].

\begin{tabular}{|l|c|c|c|}
\hline Specification & $\begin{array}{c}\text { Carbon fibers } \\
(\mathrm{C} 120-3 \mathrm{~K})\end{array}$ & $\begin{array}{c}\text { E-Glass } \\
\text { fibers }\end{array}$ & $\begin{array}{c}\text { Basalt fibers } \\
(\text { EcoB4-F210) }\end{array}$ \\
\hline Fabric weight $\left(\mathrm{g} / \mathrm{m}^{2}\right)$ & $200 \pm 10$ & 210 & $210 \pm 10$ \\
\hline $\begin{array}{l}\text { Warp construction } \\
\text { (thread count/m) }\end{array}$ & 0.31 & - & 0.56 \\
\hline $\begin{array}{l}\text { Fill construction } \\
\text { (thread count/m) }\end{array}$ & 0.33 & - & 0.66 \\
\hline Fabric thickness $(\mathrm{mm})$ & $0.25 \pm 0.02$ & - & $0.19 \sim 0.20$ \\
\hline
\end{tabular}


Table 2. Characteristics of the unsaturated polyester resin [25].

\begin{tabular}{|c|c|c|c|c|c|}
\hline Material & $\begin{array}{c}\text { Specific gravity } \\
{\left[25^{\circ} \mathrm{C}\right]}\end{array}$ & $\begin{array}{c}\text { Viscosity } \\
{\left[\mathrm{cps}, 25^{\circ} \mathrm{C}\right]}\end{array}$ & $\begin{array}{c}\text { Tensile } \\
\text { strength } \\
{[\mathrm{MPa}]}\end{array}$ & $\begin{array}{c}\text { Flexural } \\
\text { strength } \\
{[\mathrm{MPa}]}\end{array}$ & $\begin{array}{c}\text { Tensile } \\
\text { strain }(\%)\end{array}$ \\
\hline Polyester resin & $1.16 \pm 0.02$ & $1200 \pm 500$ & 63.7 & 81.3 & 5.42 \\
\hline
\end{tabular}

\subsection{Laminates Preparation and Configuration}

Hand lay-up technique (HLU) was used to produce five layers of laminates hybrid composite with various fiber configurations. Initially, a release gel is sprayed on the mold surface to a void the sticking of polymer to the surface; wood templates are used at the top and bottom of the mold plate to get good surface finish of the product. Second reinforcement in the form of woven mats is cut as per the mold size and place at the surface of mold after Perspex sheet. Then thermosetting polymer in liquid form is mixed thoroughly in suitable proportion with a prescribed hardener and poured on to the surface of mat already placed in the mold, usually at room temperature. The polymer is uniformly spread with the help of brush. Second layer of mat is then placed on the polymer surface and a roller is used to impose a mild pressure on the mat-polymer layer to remove any air trapped as well as the excess polymer present and the resin allowed to react chemically (cure) to a hard matrix. Finally, the mould is then left so that the resin will cure. The process was repeated for each layer of polymer and reinforcements. The experimental setup of the HLU technique was reported in the previous work [26] and is shown in Fig.1. The prepared hybrid laminates composite slabs were taken out from the mould after 24 hours and then specimens of suitable dimensions were prepared from the composite frame $250 \times 250 \times 5 \mathrm{~mm}^{3}$ for different mechanical and dynamic tests according to ASTM standards. The test specimens were cut by using the end mill (EM) cutter of CNC machine.
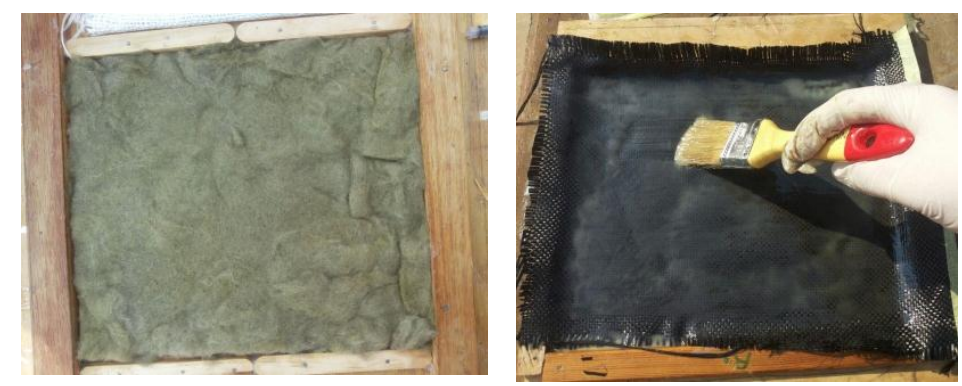

Fig.1. Hybrid laminated composites

Three types of hybrid laminates were prepared: (i) hybrid laminate where carbon fabric was located at the outermost layer (A1 A2), and glass and basalt fabrics at the innermost layer at A1 and A2 respectively; (ii) hybrid laminate where glass fabric was placed at the outermost layer (A3 A4), and carbon and basalt fabrics at the innermost layer at A3 and A4 respectively and; (iii) hybrid laminate where basalt fabric was placed at the outermost layer (A5 A6), and carbon glass fabrics at the innermost layer at A5 and A6 respectively. Also the CFRP (C), GFRP (G) and BFRP (B) were tested to compare the variation of the mechanical properties of the hybrid composite laminates. The properties of the fibers and the unsaturated polyester resin hybrid composite laminates were calculated analytically using the mixture rule [27] and are listed in Table. 3 
Table. 3 Material properties of three fibers and polyester resin composite.

\begin{tabular}{|c|c|c|c|c|}
\hline \multirow{2}{*}{ Material } & \multicolumn{4}{|c|}{ Properties } \\
\cline { 2 - 5 } & $\begin{array}{c}\text { Elasticity Modulus } \\
\text { "E" [GPa] }\end{array}$ & $\begin{array}{c}\text { Shear Modulus } \\
\text { "G" }[\mathrm{MPa}]\end{array}$ & $\begin{array}{c}\text { Density " } \\
{\left[\mathrm{g} / \mathrm{cm}^{3}\right]}\end{array}$ & $\begin{array}{c}\text { Poisson's } \\
\text { Ratio } \\
\text { "v" }\end{array}$ \\
\hline Carbon Fiber & $201 \pm 20$ & $1526 \pm 643$ & $1.73 \pm 0.01$ & 0.21 \\
\hline Basalt Fiber & $64.0 \pm 04$ & $1586 \pm 433$ & $2.59 \pm 0.01$ & 0.30 \\
\hline Glass Fiber & $69.0 \pm 14$ & $2400 \pm 402$ & $2.64 \pm 0.01$ & 0.20 \\
\hline Polyester & $2.4 \pm 0.01$ & $50 \pm 02$ & $1.25 \pm 0.01$ & 0.35 \\
\hline
\end{tabular}

The details of fiber configuration of hybrid composite laminates were reported in Table 4.

Table 4. Configurations of fiber arrangement of the hybrid composites laminate

\begin{tabular}{|c|c|c|c|c|c|}
\hline Composites & Codes & $\begin{array}{c}\text { Staking } \\
\text { sequence }\end{array}$ & $\begin{array}{c}\text { Carbon } \\
\text { contents } \\
(\text { wt. } \%)\end{array}$ & $\begin{array}{c}\text { Glass } \\
\text { contents } \\
\text { (wt.\% })\end{array}$ & $\begin{array}{c}\text { Basalt } \\
\text { contents } \\
\text { (wt.\%) }\end{array}$ \\
\hline CFRP & C & C-C-C-C-C & 60 & 0 & 0 \\
\hline GFRP & G & G-G-G-G-G & 0 & 60 & 0 \\
\hline BFRP & B & B-B-B-B-B & 0 & 0 & 60 \\
\hline CGC-1 & A1 & C-C-G-C-C & 48 & 12 & 0 \\
\hline CBC-1 & A2 & C-C-B-C-C & 48 & 0 & 12 \\
\hline GCG-2 & A3 & G-G-C-G-G & 12 & 48 & 12 \\
\hline GBG-2-1 & A4 & G-G-B-G-G & 0 & 48 & 48 \\
\hline BCB-2-1 & A5 & B-B-C-B-B & 12 & 0 & 48 \\
\hline BGB-2-1 & A6 & B-B-G-B-B & 0 & 12 & \\
\hline & where & C $=$ Carbon, G $=$ Glass and B = Basalt & \\
\hline
\end{tabular}

\subsection{Mechanical Testing Details}

\subsubsection{Tension Strength}

The test specimens were cut into strips according to ASTM D638 standard with dimensions $165 \mathrm{~mm}$ length, $19 \mathrm{~mm}$ width and $5 \mathrm{~mm}$ thickness, Fig.2. For mechanical testing, the edges of this hybrid composite laminates were finished by using emery paper. The tensile test was carried out on universal testing machine $(\mathrm{UH}-\mathrm{F} 1000 \mathrm{kN})$ with a cross head speed of 5 $\mathrm{mm} / \mathrm{min}$. The five specimens were subjected to tensile test and their values were recorded. The tension test specimens of CFRP, BFRP, and GFRP composites and hybrid composites laminates are shown in Fig.3. 

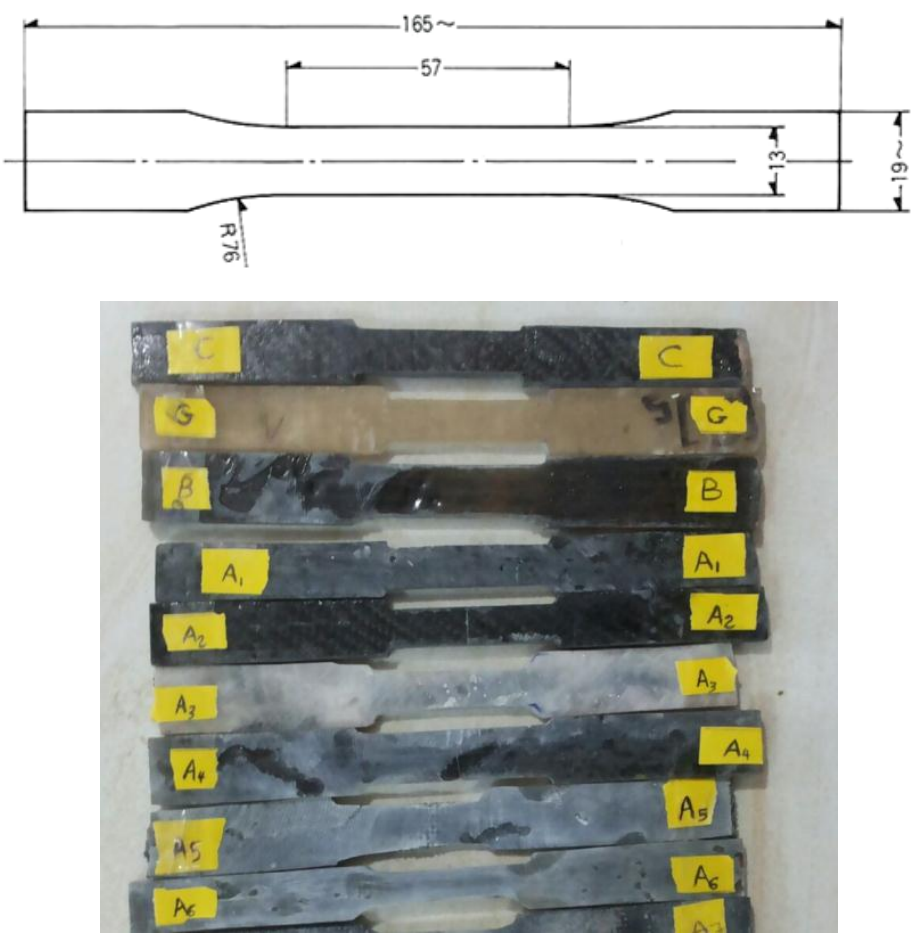

Fig.3. Tension test specimens of composites and hybrid laminate composites

\subsubsection{Impact and Flexural Strength}

Three point bending tests were used to study the flexural strength, flexural modulus and inter laminar shear strength (ILSS) of the hybrid composite laminates specimens and it was carried out according to ASTM D790 standard. Flexural modulus indicates a material's stiffness when flexed. The specimen lie on a support span and load was applied at the center by the loading nose producing bending at a specified rate $(5 \mathrm{~mm} / \mathrm{min})$. The dimensions of each specimen $(80 \mathrm{~mm} \times 10 \mathrm{~mm})$ and the thickness is $5 \mathrm{~mm}$. The flexural strength, flexural modulus and ILSS were calculated using the following equations [28].

$$
\begin{aligned}
\sigma_{f} & =\frac{3 P_{\max } L}{2 b h^{2}} \\
E_{f} & =\frac{m l^{3}}{4 b h^{3}} \\
\tau_{i l s s} & =0.75 \frac{P_{\max }}{b h}
\end{aligned}
$$

where $\mathrm{L}, \mathrm{b}, \mathrm{h}, \mathrm{P}_{\max }$, and $\mathrm{m}$ represent the support span length, width of specimen, depth of specimen, maximum flexural load, and the initial slope of the load-displacement curves of each stacking sequences of hybrid laminates composite, respectively. The interlaminar shear strength, for each stacking sequence of the composites were calculated as the means values of five recordings.

The amount of energy required to break the hybrid composite laminates specimen were determined by using the Charpy impact tester PIT Series, U-shaped pendulum of up to $150 \mathrm{~J}$. Impact test was carried out to determine the impact energy according to ASTM D256. The unit of impact strength is Joule per square millimetre and the notch depth is $1 \mathrm{~mm}$. The impact energy (J) was calculated using a dial gauge that was fitted on the impact machine. The impact test was performed with five specimens of hybrid composite, and the mean values were recorded. 


\subsection{Dynamic Testing}

\subsubsection{Modal Analysis}

Through an impact experimental test, it was determined that FRFs (Frequency Response Function) which relate the response given by the specimen when loaded with a signal, allowing for the determination of the natural frequencies and the damping factors, as shown in Fig. 4. This was done by fixing the laminate specimen in a rigid support for one end of a hybrid composite beam, vibrate the beam at mid-point. The impact hammer (piezoelectric cells B\&K, Type 8202) was used to give the input load (pulse) to the specimen, and the Spectral Analyzer was set from $0 \mathrm{~Hz}$ to $400 \mathrm{~Hz}$. This output was captured by the accelerometer (B\&K Model 4374 , mass $=2.4 \times 10^{-3} \mathrm{~kg}$ ) and together with the input sign were amplified (B\&K, Type 2835) using the spectrum analyzer BRUEL \& KJAER (B\&K, Type 2034) [29]. Since the specimens are very flexible and light, have should be given to choose the accelerometer to avoid undesirable influences on the measurements. As samples of the experimental results, the frequency response spectrums for laminated composite beam with code A1 at clamped-simple supported fixation is shown in Fig. 5.

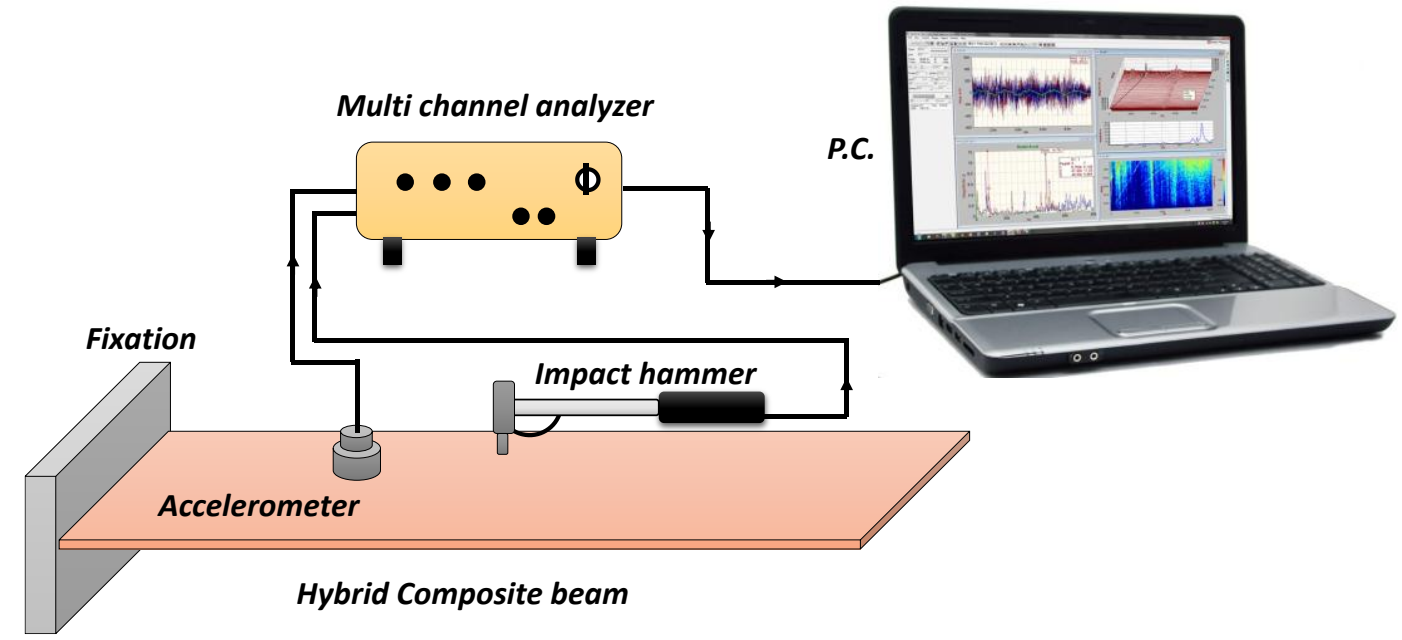

Fig. 4. An example of a measured frequency response spectrum and the coherence functions
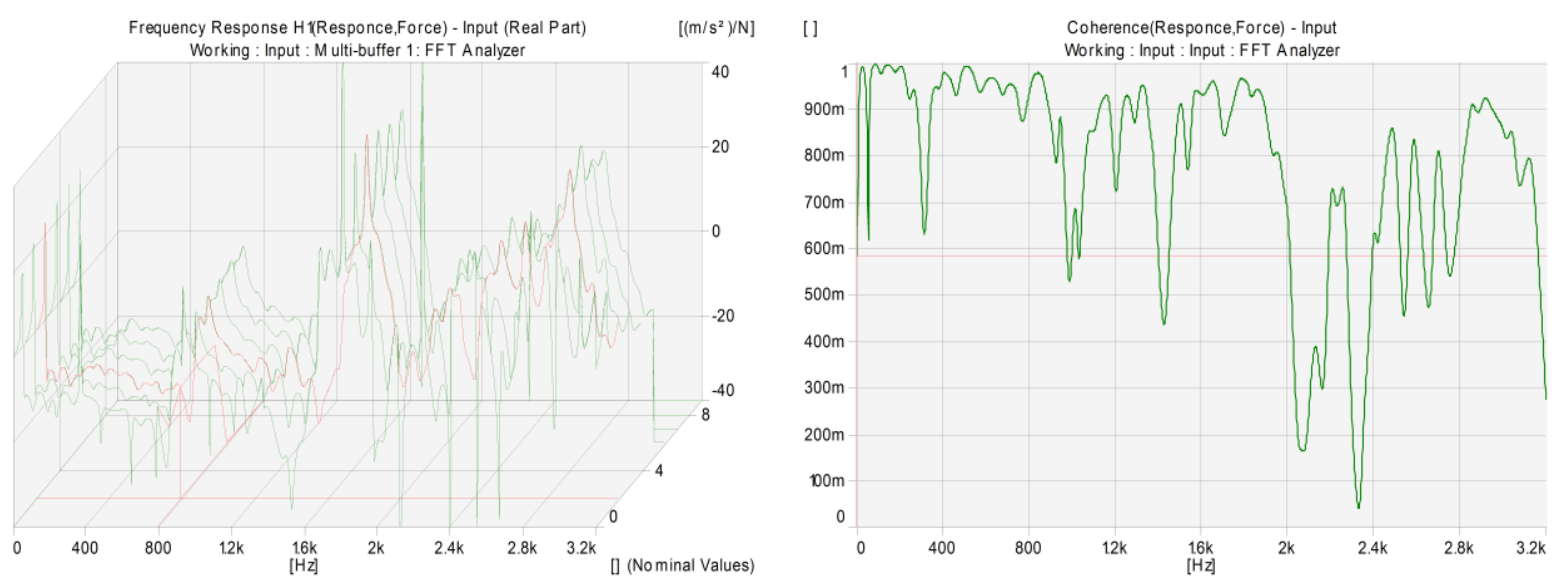

Fig.5. A sample of frequency response function and coherence function for hybrid laminates composite specimen with code A1 at clamped-simple supported. 


\subsubsection{Finite Element Modeling}

Typical hybrid composite beams of dimensions $(250 \times 50 \times 5) \mathrm{mm}^{3}$ with different configurations fiber were modeled in order to get a first estimation of the undamped natural frequencies and mode shapes for four types of boundary condition along with the edges of beams are shown in Fig.6. The equivalent elastic modulus and density of hybrid composite beams are computed [30]. A mesh element of $(20 \times 10)$ eight brick elements are utilized in the analysis and as shown in Fig. 7. The element has three degree of freedom at each node: translation in the nodal $\mathrm{X}, \mathrm{Y}$ directions and rotation about the nodal $\mathrm{Z}$ axis.

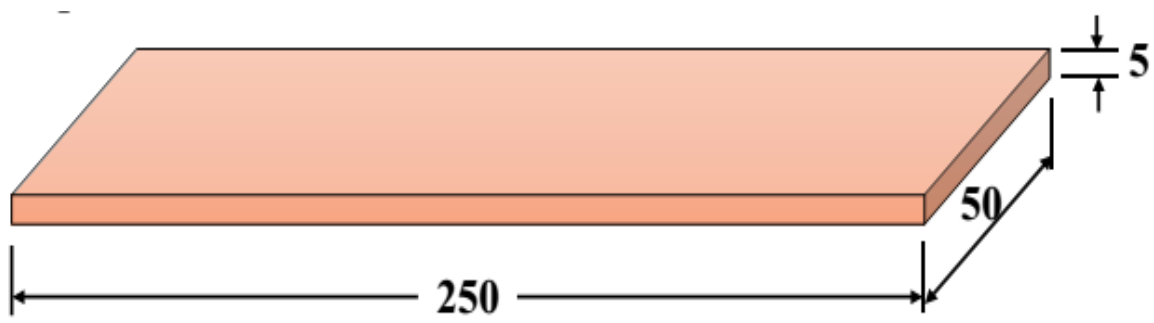

Fig. 6. Dimensions of composite beam.

Once the problem has been discretized, the next step was to find the solution for the general dynamic problem Equations $(4,5,6)$ :

$$
[M]\{\ddot{q}\}+[C]\{\dot{q}\}+[K]\{q\}=\{F(t)\}
$$

The mass and stiffness matrix of the element can be then formulated as [31]:

$$
\begin{aligned}
& {[M]^{(e)}=\rho_{c} \int[N]^{T}[N] d x d y} \\
& {[K]^{(e)}=\int[B]^{T}[D][B] d x d y}
\end{aligned}
$$

where, $\rho_{c}$ is the density of composite beam with bonded joint; $[\mathrm{N}]$ is the matrix of shape function, $[\mathrm{B}]$ is strain matrix and [D] is the elasticity matrix of composite beam, which can computed in [31], for different code number, various degree of constraints at the medium ratio of fiber volume friction $\left(\mathrm{V}_{\mathrm{f}}=60 \%\right)$. Here the equivalent flexural coefficient of the stiffness matrix of laminated layer is expressed as Equ $(7,8)[33]$ :

$$
D_{i j}=\frac{1}{3} \sum_{k=0}^{n} \bar{Q}_{i j}\left(h_{k}^{3}-h_{k-1}^{3}\right)
$$

where $\mathrm{n}$ is the number of layers, $\bar{Q}_{i j}$ is the transformed reduced stiffness, $\mathrm{h}_{\mathrm{k}}$ is the thickness of the $k^{\text {th }}$ layer and $\mathrm{i}, \mathrm{j}$ are indices varying from $1,2 \& 6$. 


$$
[D]^{-1}=\left[\begin{array}{cccccc}
1 / E_{x} & -v_{x y} / E_{x} & -v_{x z} / E_{x} & 0 & 0 & 0 \\
-v_{x y} / E_{x} & 1 / E_{y} & -v_{y z} / E_{x} & 0 & 0 & 0 \\
-v_{z x} / E_{x} & -v_{z y} / E_{x} & 1 / E_{z} & 0 & 0 & 0 \\
0 & 0 & 0 & 1 / G_{x y} & 0 & 0 \\
0 & 0 & 0 & 0 & 1 / G_{y z} & 0 \\
0 & 0 & 0 & 0 & 0 & 1 / G_{x z}
\end{array}\right]
$$

And $[\mathrm{K}]^{(\mathrm{e})}$ which depends on the damping model adopted.

The assembly of the global matrices, next step for the solution of the problem, is done by the package using the equation. For the determination of the natural frequencies of undamped system with $\mathrm{N}$ degrees of freedom, the solution is sought by solving Equ $(9,10)$ [33].

$$
[M]_{N \times N}\{\ddot{\delta}\}_{N \times 1}+[K]_{N \times N}\{\ddot{\delta}\}_{N \times 1}=0
$$

Then,

$$
\left[-\tilde{U}_{r}^{2}[M]+[K]\right]\{V\}=0
$$

where: $u_{r}^{\prime 2}$ and $\{V\}$ are the eigenpairs of dynamic analysis of hybrid composite beam.

The Eigen-values and mode shapes are computed using the FM software package ANSYS 13.0. Initially the beams were modeled in order to get a first estimation for the undamped natural frequencies and mode shape utilizing finite element type SOLID 65.

The material properties were then entered in the program and the constraint imposed to simulate a type of fixation. The numerical results using FEM were computed for different fiber configurations and boundary fixation in the case of built in at two edges of beam [29].

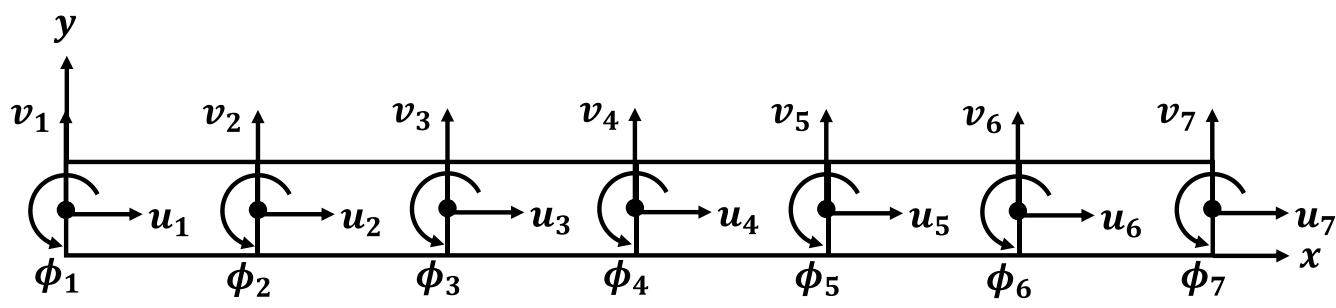

Fig. 7. Finite element model for hybrid composite beam.

\section{Results and Discussions}

\subsection{Effect of the Stacking Sequences on the Tensile Strength}

Figure 8 shows the load- displacement graphs of tension test for CFRP, GFRP, BFRP composites and some codes A1, A2, A5 hybrid laminates composites manufactured by HLU technique at room temperature to produce five layers of laminates hybrid composite with various fiber configuration. 

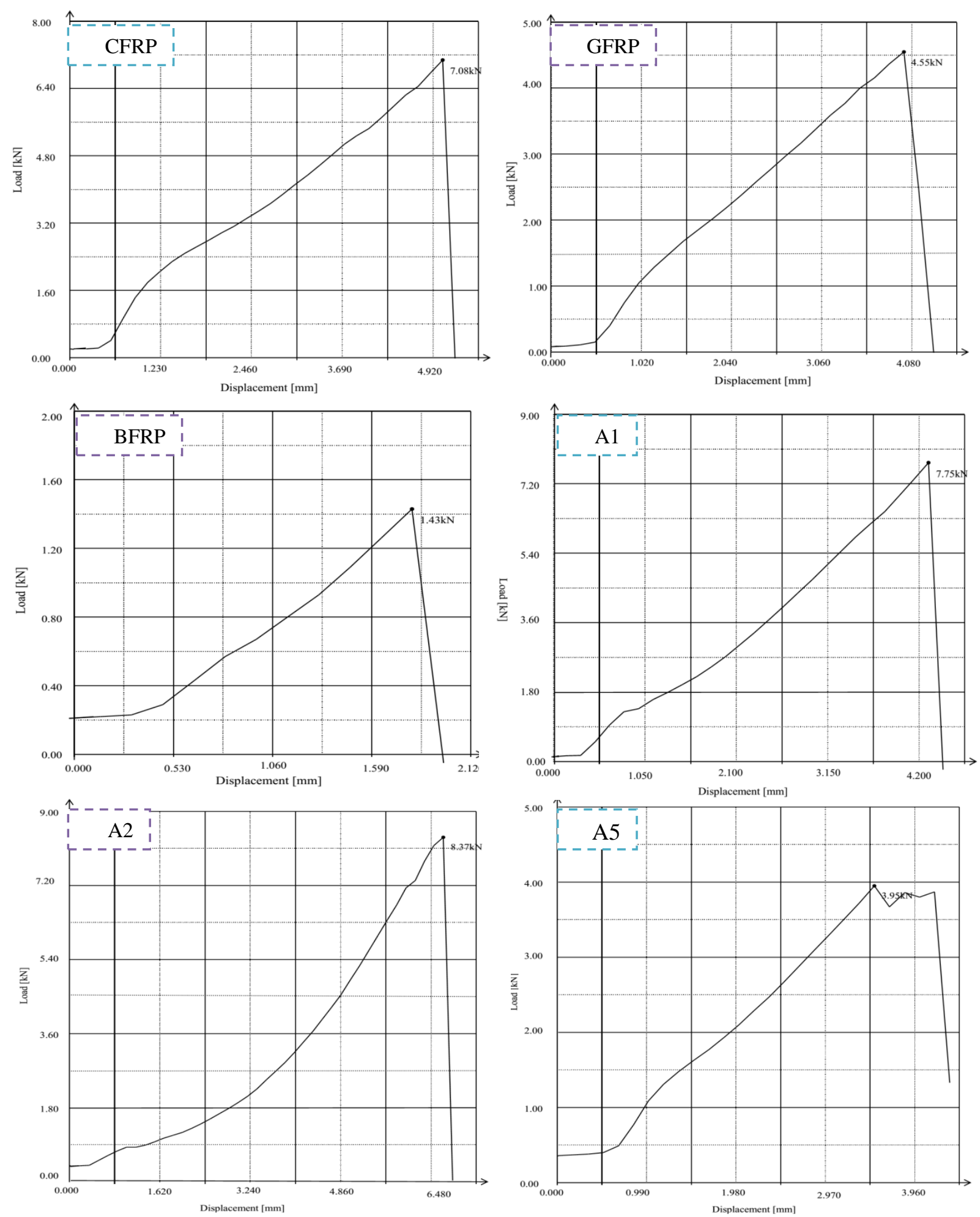

Fig. 8. Load displacement graphs of tension test for CFRP, GFRP, BFRP and some codes A1, A2, A5 hybrid laminate composites.

Tensile strength values for composites and hybrid laminates composites from codes $\mathrm{C}$ to A6 were calculated from force-stroke data and cross-sectional area of the test specimen and these values are listed in Table 5. As seen in Figure. 9 and Table. 5, the maximum tensile strength was observed at code A2, prepared with fabric configurations $[\mathrm{C}-\mathrm{C}-\mathrm{B}-\mathrm{C}-\mathrm{C}]_{\mathrm{s}}$. This hybrid laminates composite have average tensile strength of $128.76 \mathrm{MPa}$ compared to the $\mathrm{C}$ 
laminates was $99.50 \mathrm{MPa}$, while in the stacking sequence[2C-B-2C]s laminate, the B sheet is embedded between four layers of $\mathrm{C}$ sheets. The increasing in the tensile strength of this hybrid can be attributed to the basalt fibers has gained much more attention than any other conventional fibers such as (carbon or E-glass fibers) due to their enhancement of the balance of the mechanical properties at room temperature, where the basalt fiber has good strength, modulus, ductility, excellent stability and better strain to failure than carbon fiber.

According to Fig. 8 and Table 5, the values of the tensile strength for the $\mathrm{C}$ laminates were significantly greater than that of the $\mathrm{G}$ and $\mathrm{B}$ laminates. It can be noted from Table 5 that the values of the tensile strength for the $\mathrm{C}$ laminates was $99.50 \mathrm{MPa}$. However for the $\mathrm{G}$ and $\mathrm{B}$ laminates, the values of the tensile strength as were $67.68 \mathrm{MPa}$ and $21.22 \mathrm{MPa}$, respectively. The carbon laminates had the highest elastic modulus and tensile strength at room temperature than the other composites laminates. It should also be observed from Table 5 that the values of mechanical properties of the code A5 [B-B-C-B-B]s laminate is lower than that of the code A2 [C-C-B-C-C]s. The values of tensile strength of code A5 and code A2 were $50.21 \mathrm{MPa}$ and $128.76 \mathrm{MPa}$, respectively. While considering the next combinations code A3 [G-G-C-G$\mathrm{G}$ ] is $13.24 \%$ lesser than the combination code A1 [C-C-G-C-C]s. Following other combinations [C-C-G-C-C]s and [C-C-B-C-C]s it was found that [C-C-G-C-C]s is $18 \%$ greater than [C-C-G-C-C]s. Finally comparing the combinations code A5 [B-B-C-B-B]s with code A6 [B-B-G-B-B]s, was found to be $9.68 \%$ greater than code A6.

Table. 5 Tensile properties of CFRP, GFRP, BFRP and hybrid laminate composites

\begin{tabular}{|c|c|c|}
\hline Name/stacking & Laminate Codes & Tensile strength $(\mathrm{MPa})$ \\
\hline CFRP [C-C-C-C-C] & $\mathrm{C}$ & 99.50 \\
\hline GFRP [G-G-G-G-G] & $\mathrm{G}$ & 67.68 \\
\hline BFRP [B-B-B-B-B] & $\mathrm{B}$ & 21.21 \\
\hline CGC-1 [C-C-G-C-C] & A1 & 105.45 \\
\hline CBC-1 [C-C-B-C-C $]$ & $\mathrm{A} 2$ & 128.76 \\
\hline GCG-2 [G-G-C-G-G] & A3 & 91.60 \\
\hline GBG-2-1 [G-G-B-G-G] & A4 & 72.43 \\
\hline BCB-2-1 [B-B-C-B-B] & A5 & 50.21 \\
\hline BGB-2-1 [B-B-G-B-B] & A6 & 45.40 \\
\hline \multicolumn{3}{|c|}{$\mathbf{C}=$ Carbon; $\mathbf{G}=$ Glass and $\mathbf{B}=$ Basalt } \\
\hline
\end{tabular}




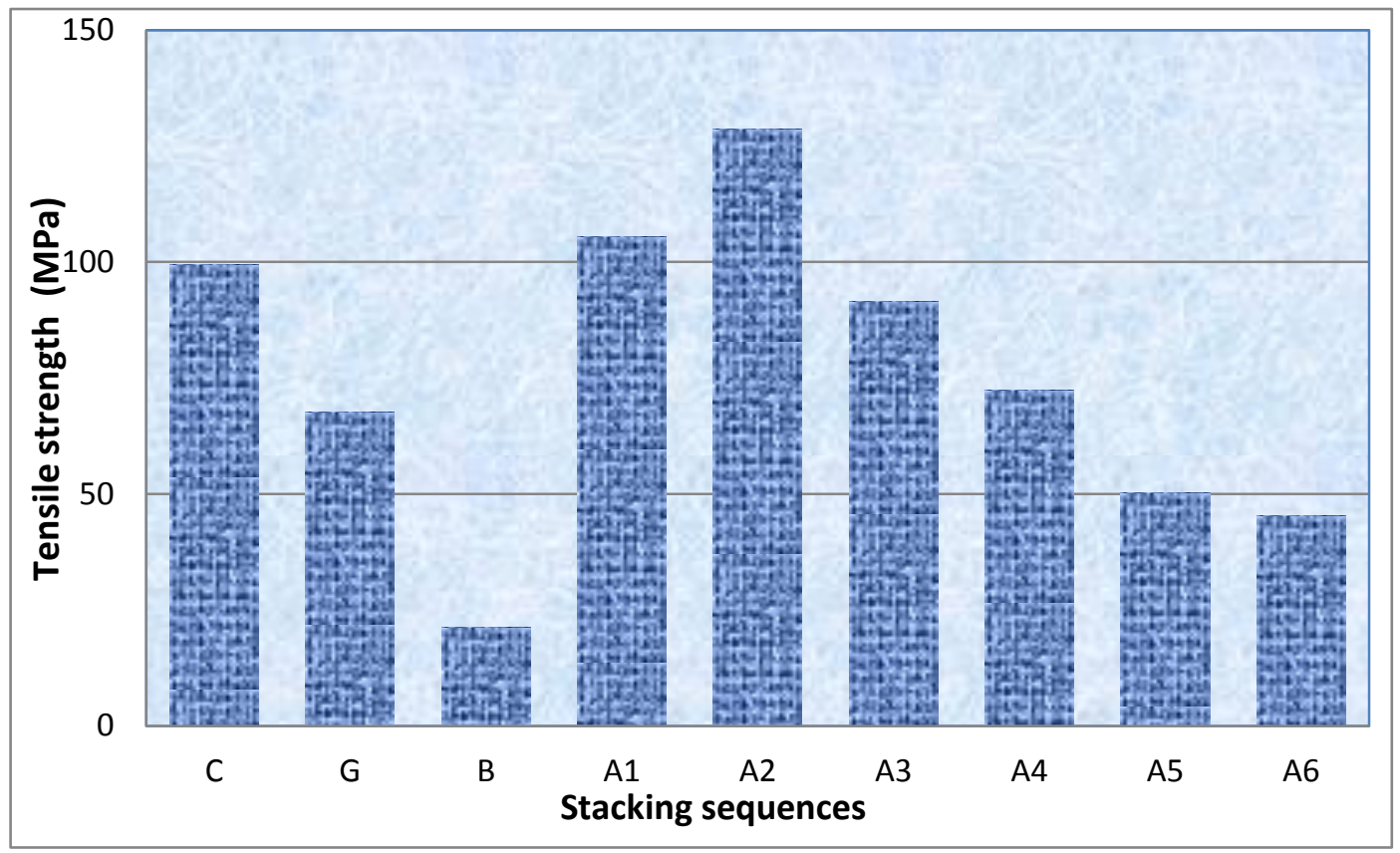

Fig. 9. Effect of stacking sequences of hybrid laminate composites on the tensile strength.

\subsection{Effect of the Stacking Sequences on the Flexural and Impact Strength}

From the testing results, flexural, ILSS and flexural modulus were calculated by using 3-point flexural formula at room Temp. by Equs: $(1,2,3)$ and typical load-displacement curves of bending test for CFRP, GFRP, BFRP composites samples and some codes A1, A2, A5 hybrid laminates composites are plotted in Fig. 10. The slope of the curves of hybrid composite laminates A1and A2 showed linear relation, a rapid increase of the flexural load, while A5 exhibited non-linear relation compared to the other stacking sequences.

Table. 6 shows the values of bending, ILSS, and flexural modulus of CFRP, GFRP, BFRP composites and hybrid laminates composites hybrid composite. Flexural modulus is an important characteristic in hybrid composite laminates, since it helps the designers to determine the maximum applied force of various stacking sequences of hybrid laminates composites. This is a measure of how material will strain and potentially even deform when applied force was applied to it. An ILSS test was carried to assess the bond strength between the fibre and the matrix in the hybrid laminated composites. It can be seen from Fig.10 and Table.6, that CFRP composite has large flexural, ILSS and flexural modulus compared to GFRP and BFRP composites. The values of flexural strength, flexural modulus and ILSS were $165 \mathrm{MPa}, 1819.42 \mathrm{MPa}, 8.55 \mathrm{MPa}$, respectively, while the flexural strength, flexural modulus and ILSS for GFRP and BFRP composites samples were $156 \mathrm{MPa}, 1680.62,7.80$ $\mathrm{MPa}$, and $128.27 \mathrm{MPa}, 1288 \mathrm{MPa}, 6.40 \mathrm{MPa}$, respectively. It is attributed to the grater breaking specific energy of CFRP composites as compared to other composites. Breaking specific energy that represents the toughness of materials and was calculated by the area under the typical load-displacement curves till the load dropped. This result indicates the good adhesion at the interface between the fibers and matrix of the hybrid composite laminates and also the reduced void content in the hybrid composite laminate. The BFRP composites had the lowest ILS strength value (6.40 MPa) compared to the all stacking sequences because its lower bond strength may have promoted a large interface between the fibre and matrix deboning. Interfacial deboning may result in interlaminar crack initiation at the interface between the matrix and fiber of hybrid composite laminates and leads to the weak in the fiber/matrix interface bonds. 

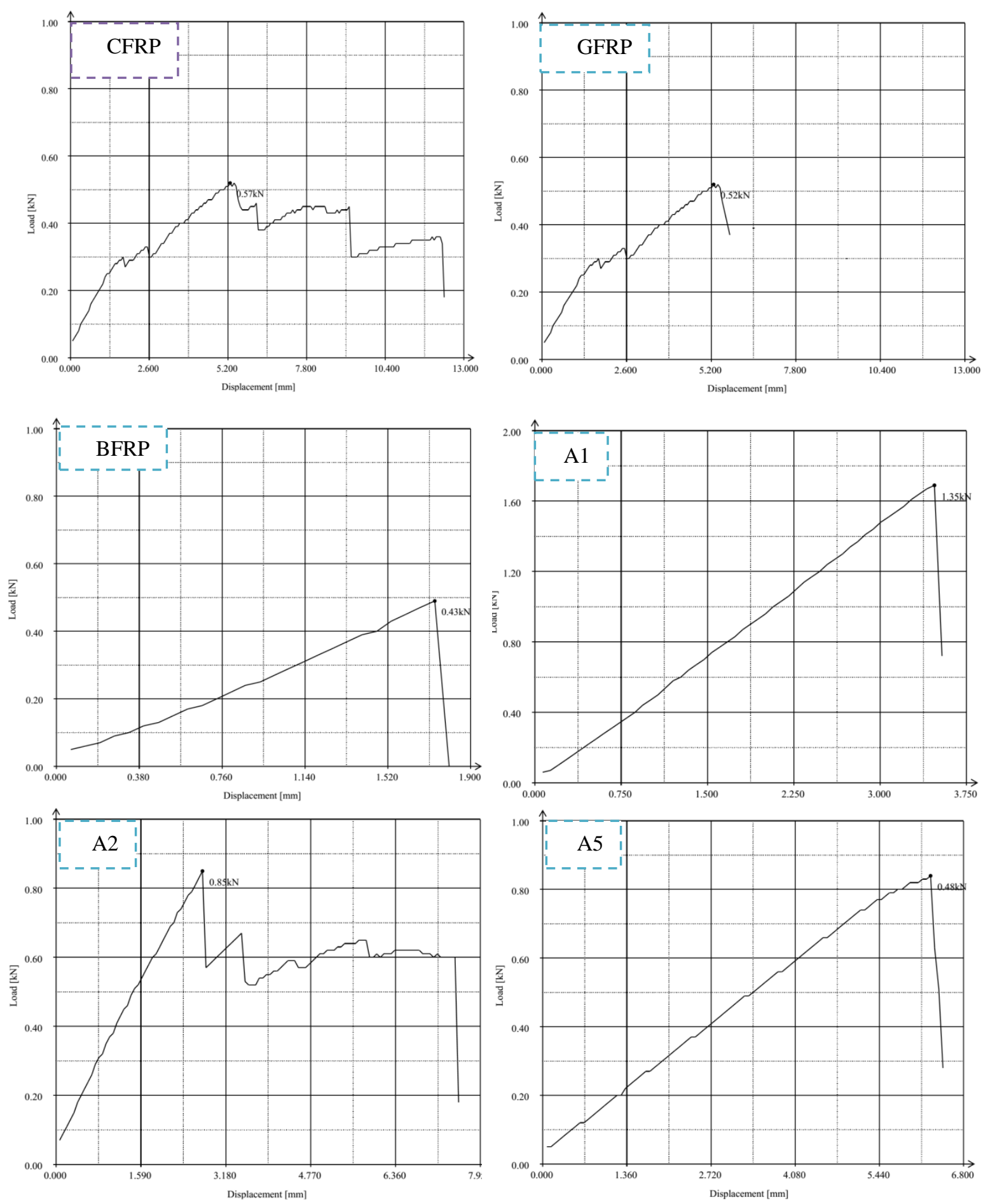

Fig. 10. Load displacement graphs of bending test for CFRP, GFRP, BFRP and some codes A1, A2, A5 hybrid laminate composites.

Also, it can be observed that from Table. 6 that the code A2 at stacking sequences [C-C-B-C-C]s have largest values of bending strength, flexural modulus and ILSS compared to the other stacking sequences of composites and hybrid composites laminates, while the maximum bending strength, flexural modulus and ILSS were $405 \mathrm{MPa}, 402 \mathrm{MPa}$, and 20.25 $\mathrm{MPa}$, respectively. Placing basalt fiber layer at the core between carbon layers leads to the increasing in the flexural strength and flexural modulus of the hybrid composites when compared to placing carbon fiber layer on the core between the basalt fiber layers. This is attributed to the higher ductility of the basalt fiber than those composites with carbon fiber at the core. The bonding between the matrix and the basalt fiber leads to the improvement in the 
mechanical properties. Finally, it has been noted from Fig.11 and Fig.12, the code A3 with stacking sequences [G-G-C-G-G]s shows $40 \%$ increase in the flexural strength and ILSS compared with code A4 at stacking [G-G-B-G-G]s, while flexural strength and ILSS of the code A6 with stacking sequences [B-B-G-B-B]s is $4.63 \%$ less than the code A5 with fiber configuration [B-B-C-B-B]s. Hence, the inclusion of carbon fabrics has played a significant role to improve the flexural strength of the hybrid composites laminate [34].

Table. 6 Flexural properties of CFRP, GFRP, BFRP and hybrid composite laminates.

\begin{tabular}{|c|c|c|c|c|}
\hline Names / stacking & $\begin{array}{c}\text { Laminate } \\
\text { Codes }\end{array}$ & $\begin{array}{c}\text { Flexural } \\
\text { strength } \\
(\mathrm{MPa})\end{array}$ & $\begin{array}{r}\text { Flexural } \\
\text { modulus } \\
(\mathrm{MPa})\end{array}$ & $\begin{array}{c}\text { ILSS strength } \\
\text { (MPa) }\end{array}$ \\
\hline CFRP $\quad[\mathrm{C}-\mathrm{C}-\mathrm{C}-\mathrm{C}-\mathrm{C}]$ & $\mathrm{C}$ & 167 & 1840.32 & 8.55 \\
\hline GFRP [G-G-G-G-G] & G & 156 & 1680.65 & 7.80 \\
\hline BFRP [B-B-B-B-B] & $\mathrm{B}$ & 128.27 & 1288 & 6.40 \\
\hline CGC-1 [C-C-G-C-C] & A1 & 230.20 & 2680.60 & 12 \\
\hline CBC-1 [C-C-B-C-C $]$ & $\mathrm{A} 2$ & 405 & 5112.32 & 20.25 \\
\hline GCG-2 [G-G-C-G-G] & A3 & 250 & 2870 & 13.10 \\
\hline GBG-2-1 [G-G-B-G-G] & A4 & 160 & 1787.43 & 8 \\
\hline BCB-2-1 [B-B-C-B-B] & A5 & 141.32 & 1400 & 7.03 \\
\hline BGB-2-1 [B-B-G-B-B] & A6 & 134.87 & 1310.15 & 6.70 \\
\hline
\end{tabular}

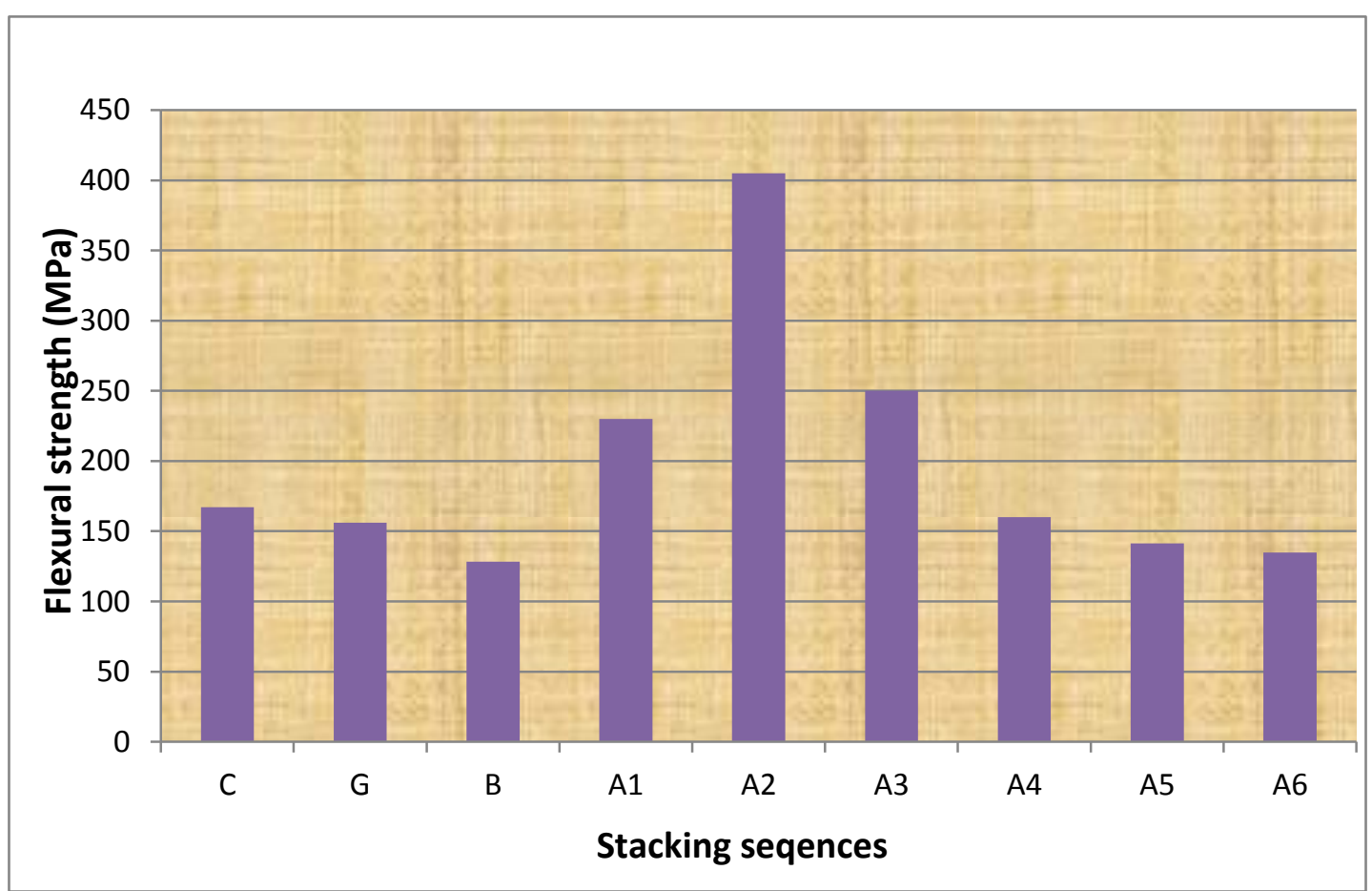

Fig. 11. Effect of stacking sequences of hybrid laminate composites on the flexural strength

$14 / 23$ 


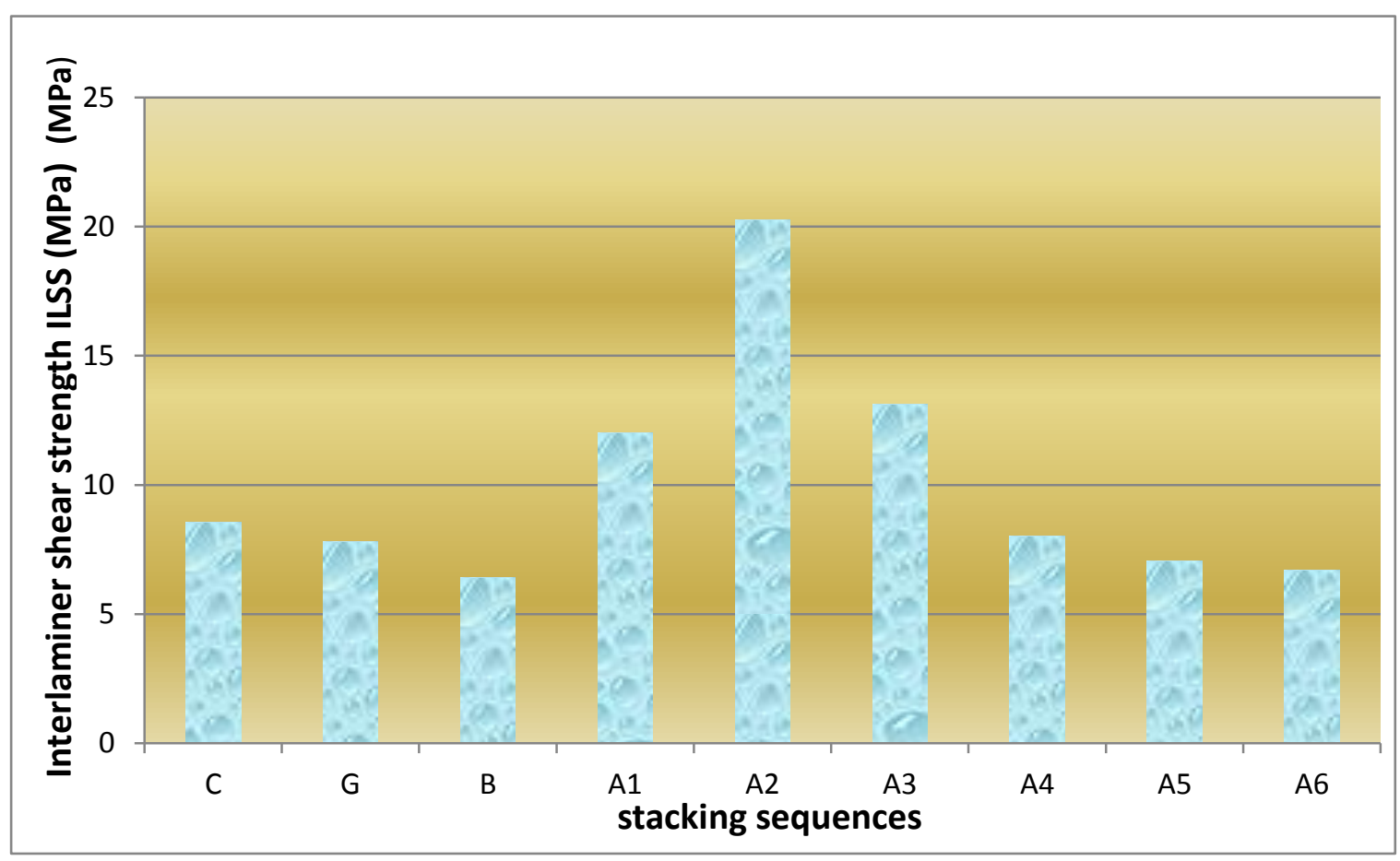

Fig. 12. Effect of stacking sequences of hybrid laminate composites on the interlamier shear strength (ILSS)

Impact strength gives an important data about the toughness of the hybrid composites materials. Impact properties of hybrid composite laminates depend on the fiber/ matrix interfacial bonding adhesion and the properties of matrix and fiber of hybrid composites. Impact properties of the composites and hybrid laminates composites were evaluated with charpy impact tests and are listed in Table 7. The fracture surfaces of CFRP, BFRP composites and hybrid composites (code A1) after impact test are shown in Fig.13.

Fig.13 (a, b) shows the fractured specimens of non-hybrid composites laminates, where fracture morphology varies. Fracture surface of CFRP specimen was surrounded by brittle fracture with flat matrix cracking and kinking compared to the BFRP composites. Fracture surface of BFRP composites was suitable for low impact strength composites with ductile behavior. The fracture mode of hybrid composites laminates code A2 was basalt fiber breakage, pull-out and delamination, as shown in Fig. 13(c). This means that hybrid composites code A2 with stacking sequences [C-C-B-C-C]s has a higher linear load displacement curve than CFRP and BFRP composites. As a result, the hybrid composites laminates code A2 has a good flexural property, as shown in Fig.11 and Fig.12. Based on the results in Table 7 and Fig.14, it can be concluded that BFRP with stacking sequences [B-B-BB]s exhibited lower impact properties than those of other stacking sequences of hybrid composite laminate, where the impact energy of the BFRP composites was 1.21 Joules.

Also, it can be noted from Fig. 14 the code A1 at stacking sequences [C-C-G-C-C]s have largest values of impact properties compared to the other composites and stacking sequences of all hybrid composite laminates. It is attributed to the better interfacial bonding between the carbon and the glass. In particular, the impact strength of $\mathrm{A} 2$ with stacking sequences [C-C-B-C-C]s is $17.23 \%$ lower than the code A1 with stacking [C-C-G-C-C] ones due to the presence of the basalt layer in the hybrid structures. There are no significant variations between stacking sequences of code A4 [2G-B-2G]s and stacking sequences of code A6 [2BG-2B]s. Compose the impact strength of code A3 at stacking [2G-C-2G]s with code A4 at stacking sequences [2G-B-2G]s was found tougher with $29.44 \%$. 

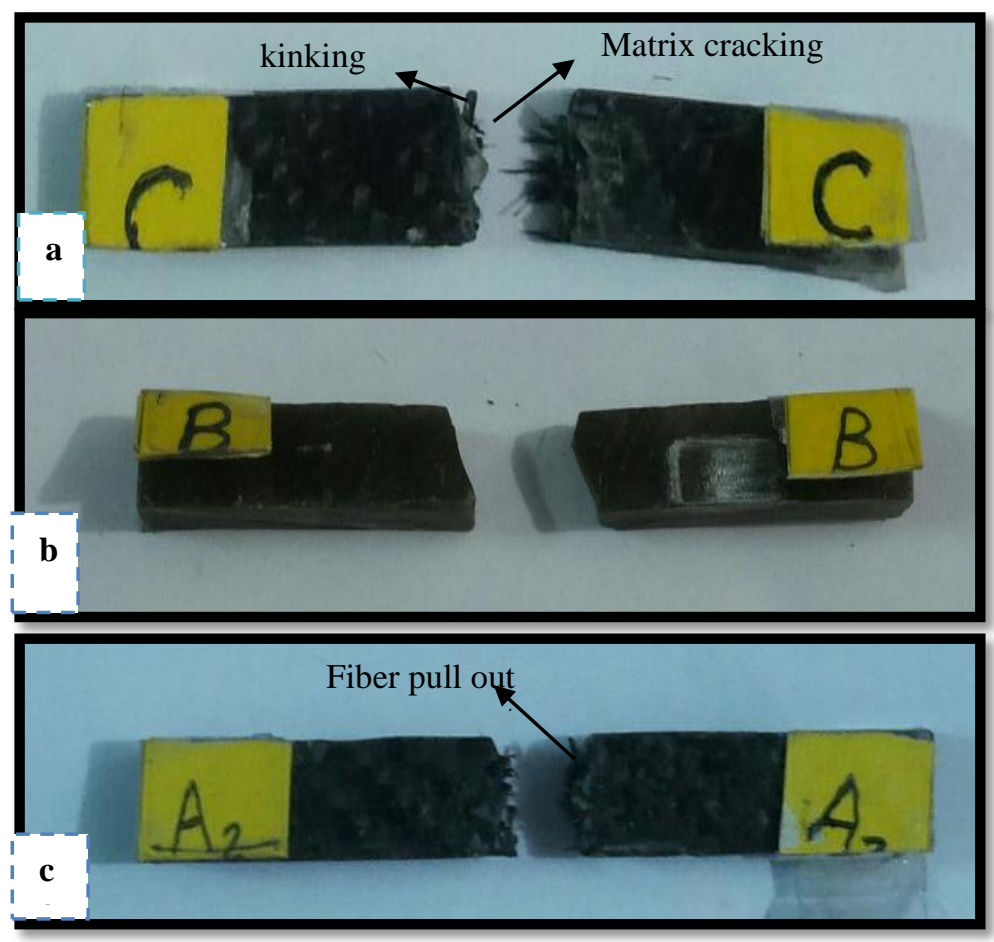

Fig. 13. Photographs of a) CFRP, b) BFRP and stacking sequence codes and c) A2 hybrid laminate composites specimens after the Charpy impact test

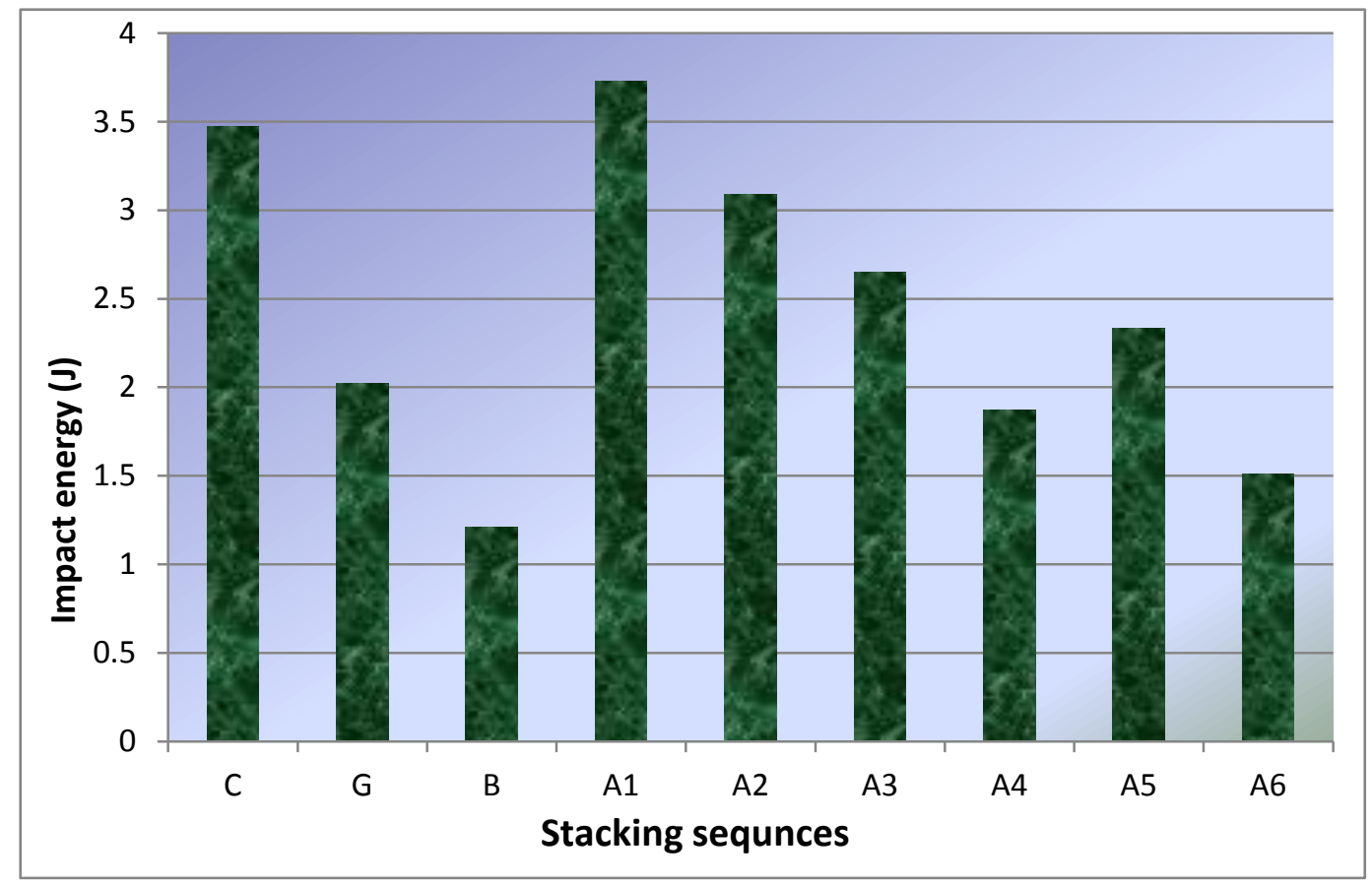

Fig. 14. Effect of stacking sequences of hybrid laminate composites on the impact energy 
Table. 7 Impact properties of CFRP, GFRP, BFRP and hybrid composite laminates

\begin{tabular}{|c|c|c|c|}
\hline Names / stacking & $\begin{array}{c}\text { Laminate } \\
\text { Codes }\end{array}$ & $\begin{array}{c}\text { Impact energy } \\
\text { (J) }\end{array}$ & $\begin{array}{c}\text { Impact strength } \\
\left(\mathrm{kJ} / \mathrm{mm}^{2}\right)\end{array}$ \\
\hline CFRP $\quad[\mathrm{C}-\mathrm{C}-\mathrm{C}-\mathrm{C}-\mathrm{C}]$ & $\mathrm{C}$ & 3.47 & 34.70 \\
\hline GFRP [G-G-G-G-G] & $G$ & 2.02 & 20.20 \\
\hline BFRP [B-B-B-B-B] & $\mathrm{B}$ & 1.21 & 12.10 \\
\hline CGC-1 [C-C-G-C-C] & A1 & 3.73 & 37.2 \\
\hline CBC-1 [C-C-B-C-C $]$ & $\mathrm{A} 2$ & 3.09 & 30.9 \\
\hline GCG-2 [G-G-C-G-G] & A3 & 2.65 & 26.5 \\
\hline GBG-2-1 [G-G-B-G-G] & A4 & 1.87 & 18.70 \\
\hline BCB-2-1 [B-B-C-B-B] & A5 & 2.33 & 23.30 \\
\hline BGB-2-1 [B-B-G-B-B] & A6 & 1.51 & 15.10 \\
\hline $\mathbf{C}=$ Carbon, $\mathbf{G}=$ Glas & id $\mathbf{B}=\mathrm{H}$ & & \\
\hline
\end{tabular}

\subsection{Effect of the Stacking Sequence and Boundary Fixations on the Natural Frequency and the Damping Factor}

The natural frequency and damping factor of laminated hybrid composite beam have been reported with various code numbers (stacking sequences) from $\mathrm{C}$ to A6 and boundary fixations (Clamped-Clamped, Clamped-Supported, Simply Supported and Clamped-Free) at the same five layers and are shown in Fig. 15 and Fig. 16. It is found that the natural frequency of all boundary fixations was very higher, otherwise the opposite edges such as (Clamped- Free) fixation was very low. The measured and the computed natural frequencies were listed in Table 8. In the presence of hybrid laminated composites experimental measurements have been carried out to verify the developed finite element software (ANSYS) of composite assembly. From Fig. 15, the natural frequency of the hybrid composites laminates decreased with the variation in codes from A1 to A6. Also, it can be observed that BFRP composites with stacking sequences [B-B-B-B-B]s has the lowest natural frequency at $178 \mathrm{~Hz}$ for (clamped-clamped) fixations compared to the other stacking sequences, while the CFRP composite specimen with code $\mathrm{C}$ [C-C-C-C-C]s has the highest value $(472 \mathrm{~Hz})$ due to the maximum values of flexural elastic modulus and stiffness and low density at this orientation respectively. The BFRP composites specimen gives better resistance to vibration than other stacking sequences of hybrid composite laminates. The code $G$ with stacking sequences [G-G-G-G-G]s has a natural frequency of $404 \mathrm{~Hz}$. No significant difference between no hybrid composites with code $\mathrm{G}$ and hybrid composites with code $\mathrm{A} 3$.

Furthermore, it was observed that the code A5 with stacking sequences [B-B-C-B-B]s, shows $56 \%$ increase in the natural frequency than that of code A6 at stacking [G-G-B-G-G]s compared to the conventional BFRP composites. Meanwhile, natural frequency of the hybrid composites with code $\mathrm{A} 1$ at stacking seqences [C-C-G-C-C]s was $3.45 \%$ less than the CFRP composites with code $\mathrm{C}$ at fiber configuration [C-C-C-C-C]s. In view of different fixation, the rate of change of the eigen-frequencies via different fixations are relatively high compared 
with the rate of change due to the use of the various code numbers of fiber orientations as shown in Fig.15 and Table 8.

On the other hand, from Fig. 16, the damping factor of the BFRP composites specimen has the highest damping factor $(0.227)$ among to the other codes, while the specimen with code $\mathrm{C}$ [C-C-C-C-C]s has the lowest values (0.061). The damping factor of the hybrid composites with code A4 with stacking sequences [G-G-B-G-G]s was higher compared to the code A3 with stacking sequences [G-G-C-G-G]s. The hybrid composites laminates with code A2 [C-C-B-C-C]s exhibits higher damping factor among to the code A1 with stacking sequences [C-C-G-C-C]s compared to the non-hybrid CFRP composite. It is attributed to the basalt fibers have high density, low stiffness values than carbon fibers. These variations depend mainly on the magnitude of acute angles between the staking sequence type and boundary fixations. Thus the eigen-parameter may be controlled by changing the fiber type, staking sequence and boundary fixations. The mode shapes give the data about the dynamic response of the hybrid composite laminates under various stacking sequence, boundary fixations and natural frequencies. Mode shapes of code A2 with stacking sequences [C-C-B-C-C]s for the first case (Clamped - Free ) and the second case (Clamped - Clamped) are shown in Fig. 17. The experimental results verified the numerical values, obtained from the solution of Eq. 7 . The numerical results of the present paper have been found to be in a good conformity with the experimental results with maximum and minimum difference ratio at $8 \%$ and $15 \%$.

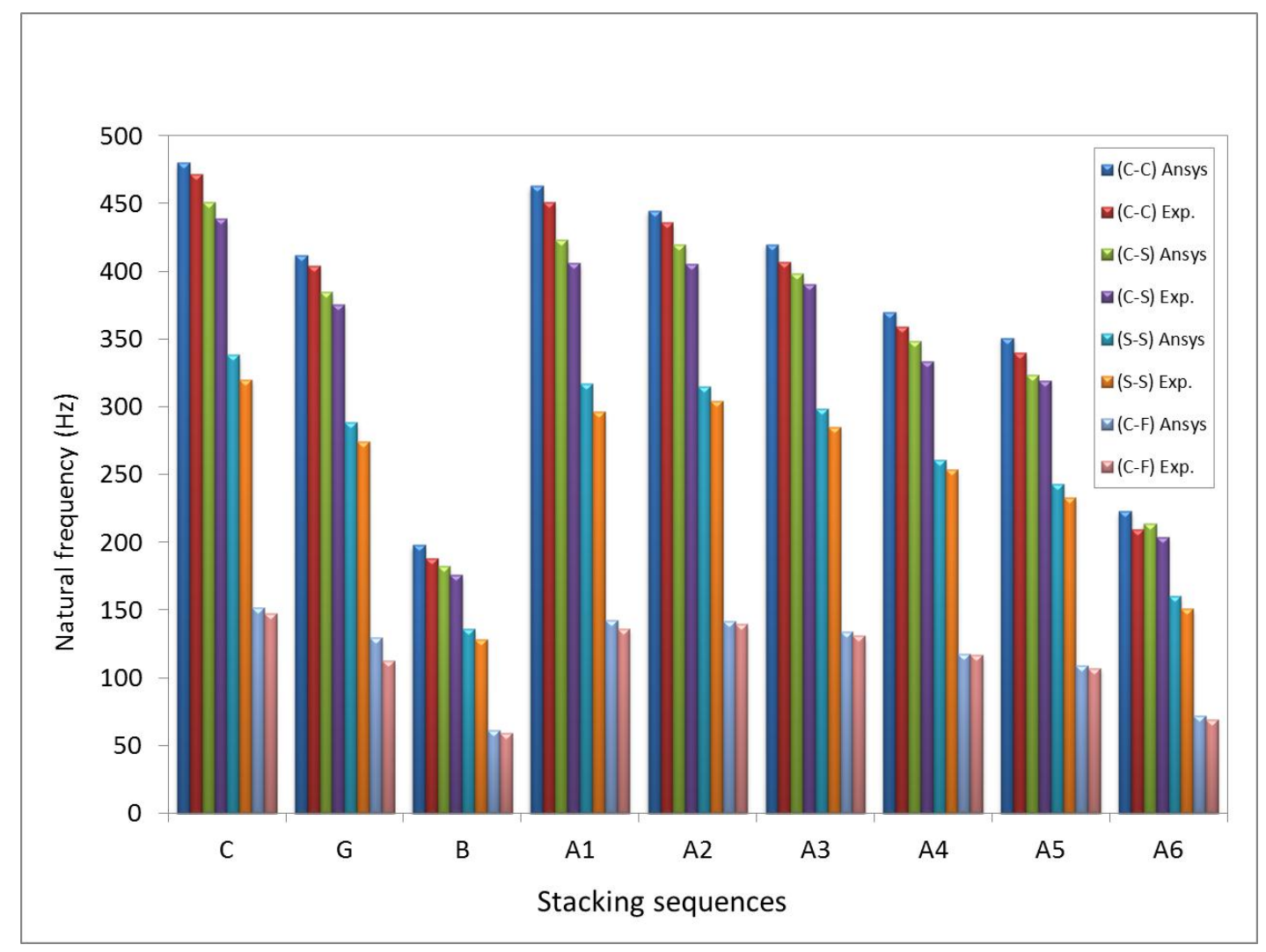

Fig. 15. Natural frequency at different boundary fixations and various stacking sequences 


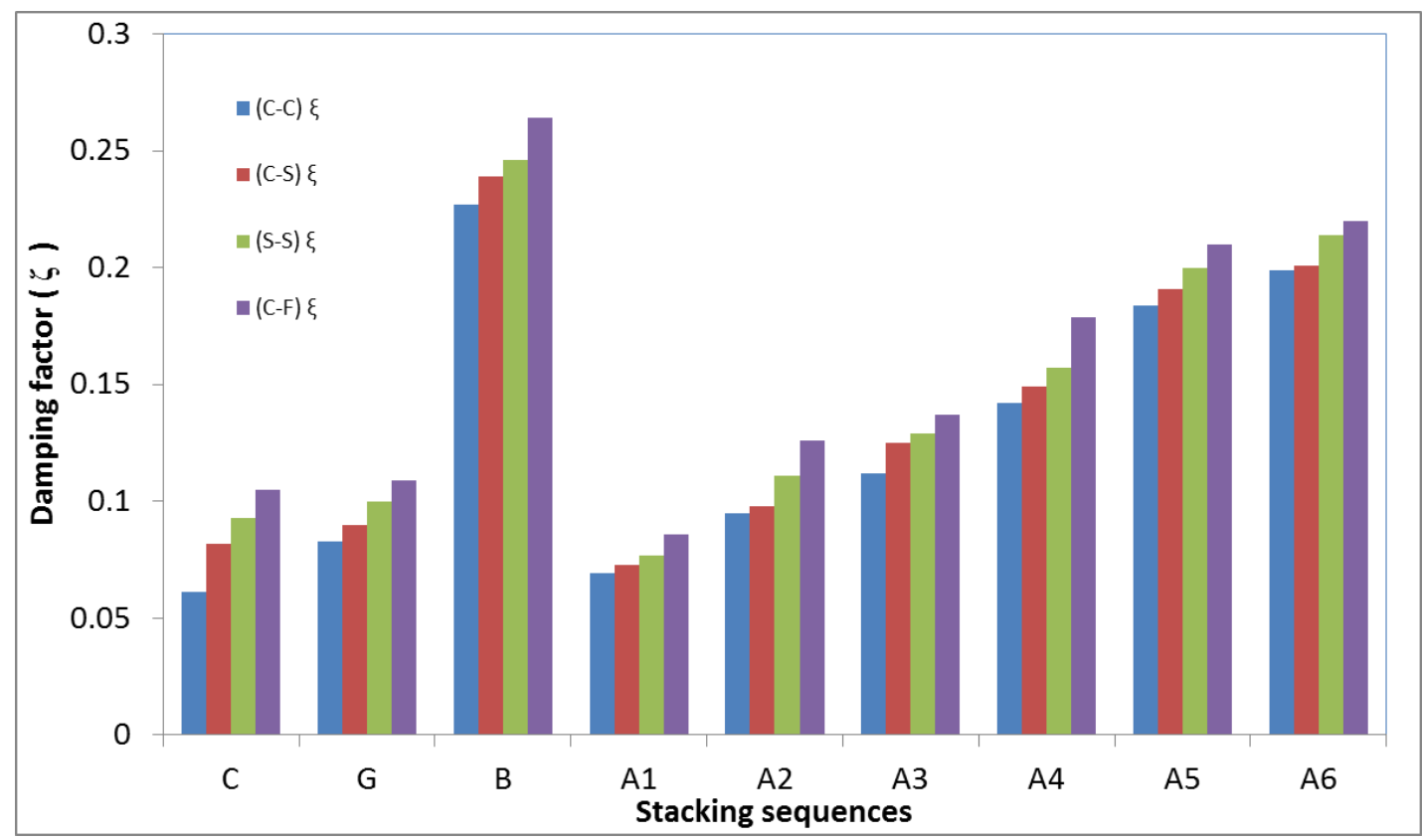

Fig. 16. Damping factor at different boundary fixations and various stacking sequences

Table. 8 Natural frequencies in $(\mathrm{Hz})$ at different boundary conditions and various staking sequences.

\begin{tabular}{|c|c|c|c|c|c|c|c|c|}
\hline \multirow{2}{*}{$\begin{array}{c}\text { Specimens } \\
\text { Codes }\end{array}$} & \multicolumn{2}{|c|}{$(\mathbf{C - C})$} & \multicolumn{2}{|c|}{ (C-S) } & \multicolumn{2}{c|}{ (S-S) } & \multicolumn{2}{c|}{ (C-F) } \\
\cline { 2 - 9 } & Ansys & Exp. & Ansys & Exp. & Ansys & Exp. & Ansys & Exp. \\
\hline C & 480 & 472 & 451.2 & 438.9 & 338.4 & 320.4 & 152.1 & 147.4 \\
\hline G & 412 & 404 & 384.8 & 375.7 & 288.7 & 274.3 & 129.9 & 113.0 \\
\hline B & 195 & 178 & 182.4 & 176.1 & 136.6 & 128.6 & 61.5 & 59.2 \\
\hline A1 & 463 & 451 & 423.2 & 405.9 & 317.4 & 296.3 & 142.8 & 136.3 \\
\hline A2 & 445 & 436 & 420.1 & 405.5 & 315.1 & 304.1 & 141.8 & 139.8 \\
\hline A3 & 420 & 407 & 398.2 & 390.6 & 298.6 & 285.2 & 134.4 & 131.2 \\
\hline A4 & 370 & 359 & 348.3 & 333.8 & 261.1 & 253.7 & 117.5 & 116.7 \\
\hline A5 & 351 & 340 & 323.9 & 319.6 & 242.9 & 233.3 & 109.3 & 107.3 \\
\hline A6 & 223 & 210 & 214.1 & 203.7 & 160.5 & 151.2 & 72.2 & 69.6 \\
\hline
\end{tabular}


Table. 9 Damping factor and natural frequency at different boundary conditions and various staking sequences (Experimental result).

\begin{tabular}{|c|c|c|c|c|c|c|c|c|}
\hline \multirow{2}{*}{$\begin{array}{c}\text { Specimens } \\
\text { Codes }\end{array}$} & \multicolumn{2}{|c|}{ (C-C) } & \multicolumn{2}{c|}{ (C-S) } & \multicolumn{2}{c|}{ (S-S) } & \multicolumn{2}{c|}{ (C-F) } \\
\cline { 2 - 10 } & $\xi$ & Exp. & $\xi$ & Exp. & $\xi$ & Exp. & $\xi$ & Exp. \\
\hline C & 0.061 & 472 & 0.082 & 438.9 & 0.093 & 320.4 & 0.105 & 147.4 \\
\hline G & 0.083 & 407 & 0.09 & 390.6 & 0.1 & 285.2 & 0.109 & 131.2 \\
\hline B & 0.227 & 178 & 0.239 & 176.1 & 0.246 & 128.6 & 0.264 & 59.2 \\
\hline A1 & 0.069 & 451 & 0.073 & 405.9 & 0.077 & 296.3 & 0.086 & 136.3 \\
\hline A2 & 0.095 & 436 & 0.098 & 405.5 & 0.111 & 304.1 & 0.126 & 139.8 \\
\hline A3 & 0.112 & 407 & 0.125 & 390.6 & 0.129 & 285.2 & 0.137 & 131.2 \\
\hline A4 & 0.142 & 359 & 0.149 & 333.8 & 0.157 & 253.7 & 0.179 & 116.7 \\
\hline A5 & 0.184 & 340 & 0.191 & 319.6 & 0.2 & 233.3 & 0.21 & 107.3 \\
\hline A6 & 0.199 & 210 & 0.201 & 203.7 & 0.214 & 151.2 & 0.22 & 69.6 \\
\hline
\end{tabular}

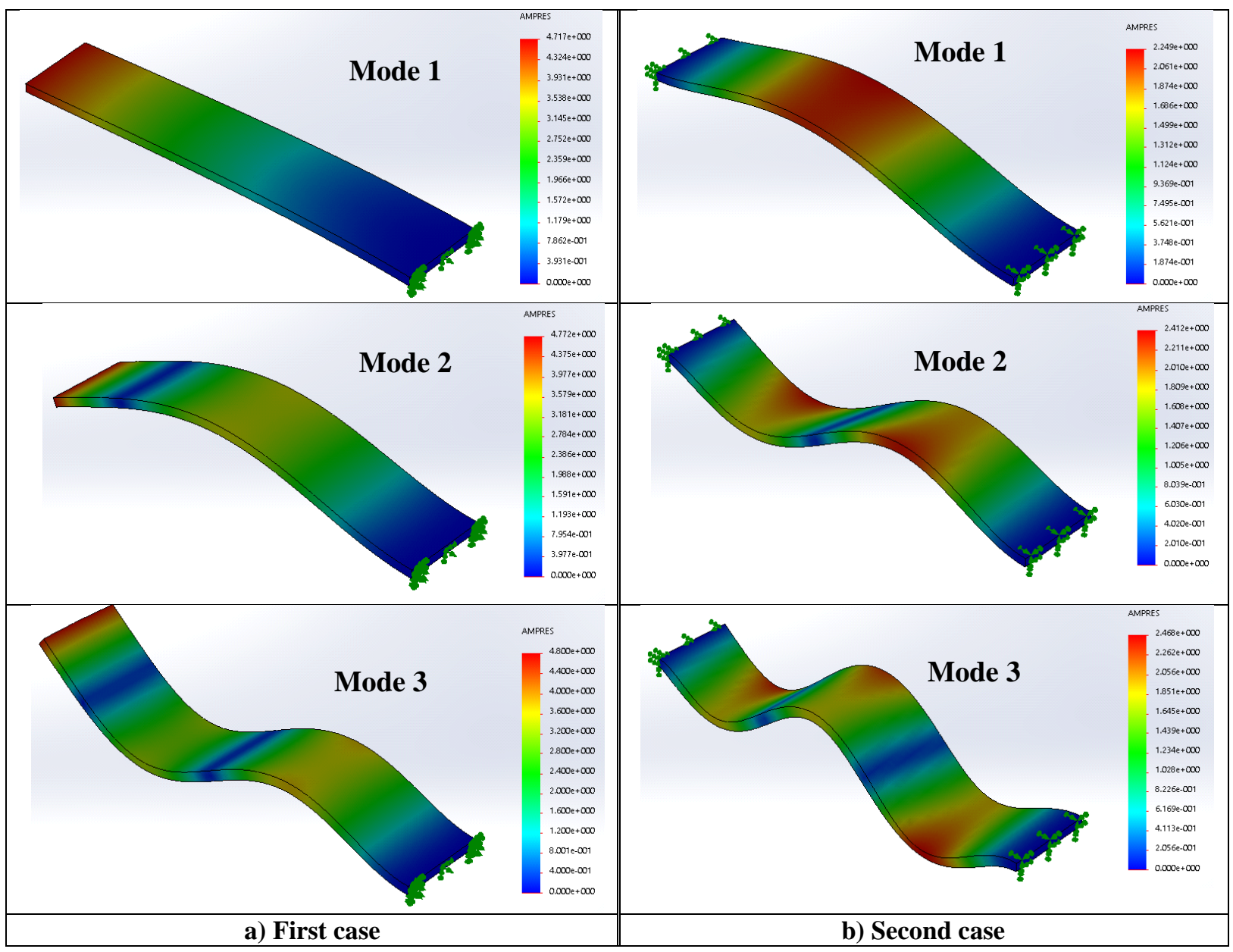

Fig. 17. Mode shapes of the hybrid laminate composites code A2 for a) First case (Clamped-Free) and b) Second case (Clamped-Clamped) 


\section{Conclusions}

The tensile strength of hybrid composite laminates with the stacking sequence $[2 \mathrm{C} / \mathrm{B} / 2 \mathrm{C}]_{\mathrm{S}}$ was higher $(128.76 \mathrm{MPa})$ than the basalt fabrics $(21.21 \mathrm{MPa})$, E-glass fabrics (67.68 $\mathrm{MPa})$, carbon fabrics $(99.50 \mathrm{MPa})$ composites and other stacking sequences of the hybrid laminates composite. The flexural strength, flexural modulus and ILSS have the largest values (405 $\mathrm{MPa}, 5112.32 \mathrm{MPa}, 20.25 \mathrm{MPa}$ ), respectively for the hybrid composite laminate at code A2 with stacking sequence $[2 \mathrm{C} / \mathrm{B} / 2 \mathrm{C}]_{\mathrm{S}}$ compared to the other fiber configurations. The presence of $\mathrm{BF}$ in the polyester/carbon laminates composite has a positive impact to improve the tensile, flexural and ILS strength. However, the presence of BF fibre in the polyester/glass hybrid composite laminates causes to decrease the tensile and flexural strength than the GFRP laminates composite. Also, it has been observed that the code A1 with stacking sequences [CC-G-C-C]s have largest value $\left(37.20 \mathrm{~kJ} / \mathrm{mm}^{2}\right)$ of impact strength compared to the other stacking sequences of all hybrid composite laminates. The fracture surface of hybrid composites laminates of code A2 was basalt fiber pull-out, breakage and delamination, while the fracture mode of CFRP composites was domained by brittle fracture with kinking and cracking among the BFRP composites.

The BFRP composites specimen with code B has the lowest natural frequency $(178 \mathrm{~Hz})$ compared to the other codes, while the CFRP composites specimen with code $\mathrm{C}$ has the highest values $(472 \mathrm{~Hz})$. The hybrid composites laminates with code A2 [C-C-B-C-C]s exhibits higher damping factor (0.09) among to the code A1 (0.069) with stacking sequences [C-C-G-C-C]s compared to the non-hybrid CFRP composites (0.061). The numerical results by finite element method have been found to be in a good conformity with the experimental results with maximum difference ratio at $15 \%$. Also, the results show that the changes of the dynamic response provide a proper indicator for predicting the current state of adhesive bonded joint.

\section{References}

[1] Vogelesang, L. B., Vlot, A., Development of fibre metal laminates for advanced aerospace structure, J. Mater. Process Technol., Vol.103, 2000; pp. 1-5.

[2] Kim, K. S., Bae, K. M., Oh, S. Y., Seo, M. K., Kang, C. G., Park, S. J., Trend of carbon fiber reinforced composites for lightweight vehicles, Elastomers Composites, Vol.47, 2012; pp.65-74.

[3] Ahmad, F., Ridzuan, M., Latif, A., Hybrid Composites for Engineering Applications, in Composite Technologies. Woodhead Publish. 2004, pp.545-550.

[4] Lopresto, V., Leone, C., \& De Iorio, I. Mechanical characterisation of basalt fibre reinforced plastic. Composit. Part B, Vol 42, Iss 4, 2011, pp.717-723.

[5] Rajkumar, S., Marimuthu, K., Experimental Research on the Fundamental Mechanical Properties of Basalt Fiber Reinforcement with Epoxy, J. Innov. Res. in Sci., Engin. \& Technl., vol. 3(11), 2014, pp.123-144.

[6] Derogate, A., and Pergoretti, A., Flexural and impact behaviour of carbon/basalt fibers hybrid laminates, J. Comp. Mat., vo. 1(2), 2016, pp.1-30.

[7] Jagannatha, T. D., Harish, G., Influence of Carbon \& Glass Fiber Reinforcements on Flexural Strength of Epoxy Matrix Polymer Hybrid Composites, Int. J. Eng. Res. \& Applic., vol 5(4) 2015, pp.109-112.

[8] Amuthakkannan, P., Manikandan, V., Uthayakumar, M., Mechanical Properties of Basalt and Glass Fiber Reinforced Polymer Hybrid Composites, J. Advan. Micros. Res., Vol. 9, 2014, p.1-6.

[9] Subagia, A., Kim, Y., A study on flexural properties of carbon-basalt/epoxy hybrid composites, Microscopy Research vol.8, 2014, p.14-21. 
[10] De Rosa, I, Marra, F., Pulci, G., Santulli, C., Sarasini, F., Tirillò, J., Valente, M., Postimpact mechanical characterisation of E-glass/basalt woven fabric interply hybrid laminates, eXPRESS Poly., Lett. 5(5), 2011, p.449-459.

[11] Soares, B., Preto, R., Sousaa, L., Reis, L., Mechanical behavior of basalt fibers in a basalt-UP composite, Proced. Struct. Integ. 1, 2016, pp.082-089.

[12] Turla, P., Kumar, S., Reddy, H., Shekar, K., Interlaminar Shear Strength of Carbon Fiber and Glass Fiber Reinforced Epoxy Matrix Hybrid Composite, I. J. Research in Eng. \& Advan.Technol., 2(2), 2014, pp.180-190.

[13] Hawileh, R, Abdalla, J, Hasan, S, Ziyada, M, Abu-Obeidah, A., Models for predicting elastic modulus and tensile strength of carbon, basalt and hybrid carbon-basalt FRP laminates at elevated temperatures, Construc. \& Build. Materi., vol.114, 2016, pp. 364373.

[14] GuruRaja, M. N., HariRao, A. N., Influence of Angle Ply Orientation on Tensile Properties of Carbon/Glass Hybrid Composite, J. of Miner. and Mater., Charact. \& Engin., vol. 1, 2013, p.231-235.

[15] Fiore, V, Scalici, T, Calabrese, L, Valenza, A, Proverbio, E., Effect of external basalt layers on durability behaviour of flax reinforced composites, Composi. Part B vol. 84, 2016, p. 258-265.

[16] Santiago R, Cantwell, W, Alves, M., Impact on thermoplastic fibre-metal laminates: Experimental observations, Compos. Struct. vol.159, 2017, pp.800-817

[17] Mohammed, O., Vibration analysis of hybrid laminated composite beam, Vibration analysis of hybrid laminated composite beam, Al-Rafid. Engin., Vol. 21 No. 4, 2013, pp. 210-216.

[18] Aly, M., Goda, I., and Hassan, G., Experimental Investigation of the Dynamic Characteristics of Laminated Composite Beams, I. J. Mechan., \& Mechatrn., JMMEIJENS, Vol: 10 No: 03, 2014, pp.40-49.

[19] Afrough, M., Pandya, T., Daryadel, S., Mantena, P., Dynamic Response of Pultruded Glass-Graphite/Epoxy Hybrid Composites Subjected to Transverse High Strain-Rate Compression Loading, Mater. Scien \& Applic., vol. 6, 2015, pp.953-962.

[20] Yokoyama, T., Nakai, K. and Odamura, T., High Strain-Rate Compressive Characteristics of a Unidirectional Carbon/Epoxy Composite: Effect of Loading Directions. In: Gdoutos, E.E., Ed., Experi. Analys. of Nano and Engin. Materi. \& Struct., , Dordrecht, 2007, pp.681-682.

[21] Murugana, R, Rameshb, R., Padmanabhanc, K., Investigation on Static and Dynamic Mechanical Properties of Epoxy Based Woven Fabric Glass/Carbon Hybrid Composite Laminates, Proce. Engin. vol. 97, 2014 , pp. 459-468.

[22] Jacob, M, Francis B, Thomos S, Varughese KT, Dynamic Mechanical analysis of sisal/oil palm hybrid fibre reinforced natural rubber composites. Polym Compos vol. 27(6), 2006, pp.671-80.

[23] Jacob, M, Francis, B, Thomos, S, Varughese, K. T, Thomos, S, The effect of silane coupling agents on the viscoelastic properties of rubber biocomposites, Macromol Mater., Eng. Vol. 291(9), 2006, pp. 1119-26.

[24] Jawad M, Abdul Khalil H P S, Omar S Alattas, Woven hybrid biocomposites: Dynamic mechanical and thermal properties, Composi.: Part A vol. 43, 2012, pp.288-293

[25] Putic, S., Mechanical properties of polymeric composite materials, Faculty of Technology and Metallurgy, Belgrade, 2006.

[26] EL-Wazery, S, M., EL-Elamy, I. M., Zoalfakar, H. S., "Experimental investigation on the mechanical behavior of glass fiber reinforced polyester resin composites", Proceeding of International Conference of Engineering Sciences \& Applications (ICESA), 29-31 January 2016, Aswan- Egypt, pp.324-332.

[27] Huntsman advanced materials (Europe) BVBA, B 3078 Everberg. 
[28] ASTM International, standard test methods for flexural properties of unreinforced and reinforced plastics and electrical insulating materials. In:D70. West Conshohocken, PA: ASTM International; 2007.

[29] Hamada, A., Ghonam, A., and EL-Elamy, M., Dynamic Analysis of an Adhesively Bonded Joint for Composite Structures", The $12^{\text {th }}$ International Conference on Aerospace Sciences and Aviation Technology (ASAT-12), Military Technical College, Cairo, Egypt, 29-31 May, 2007. pp.312-318.

[30] Hatch, R. M., Vibration Simulation Using Matlab and Ansys" Chapman and Hall/CRC, (2001).

[31] Tita,V., Carvalho, J., and Lirani, J.,Theoretical and Experimental Dynamic Analysis of Fiber Reinforced Composite Beams, J.of the Braz. Soc. Mech. Sci.\& Eng.;XV (3), 2003, pp.106-112.

[32] Chandra, R., Singh, S., Gupta, K., A study of damping in fiber-reinforced composites", J Sound and Vibr., vol.262, 2003, pp.475-496.

[33] Jones, R., Mechanics of composite materials, Scripta Book Company,(1975).

[34] Poyyathappan, K., Bhaskar, G., Pazhanivel, K., and Venkatesan, N., Tensile an flexural studies on glass-carbon hybrid composites subjected to low frequency cyclic loading, I. J. of Engine. \& Technol., vol. 6(1), 2014, pp.83-90. 